\section{GI physiology \\ PWE-001 AMBULANT HIGH RESOLUTION MANOMETRY STUDIES OF THE MECHANISMS OF GASTRO-OESOPHAGEAL REFLUX IN PATIENTS WITH AND WITHOUT EVIDENCE OF HIATUS HERNIA}

doi:10.1136/gutjnl-2012-302514d.1

B T Theron, ${ }^{*}$ A Yamamoto, H Aladin, N Trudgill. Department of Gastroenterology, Sandwell Hospital, West Bromwich, UK

Introduction Recent studies have shown that high resolution manometry (HRM) detects more transient lower oesophageal relaxation (tLOSR) than the established sleeve sensor. Previous studies using the sleeve sensor have suggested that when a hiatus hernia $(\mathrm{HH})$ is present and in patients with more severe oesophagitis, gastro-oesophageal reflux (GOR) more commonly occurs due to mechanisms other than TLOSR. We have developed a unique ambulatory HRM system to study mechanisms of GORD under more physiological conditions in patients with reflux oesophagitis or Barrett's oesophagus, with and without hiatus hernia.

Methods 10 patients with $\mathrm{HH}$ and six patients without $\mathrm{HH}$ (all with an endoscopic diagnosis of reflux oesophagitis) were studied after a fast for at least $4 \mathrm{~h}$. A 36 channel solid state HRM/impedance catheter was placed spanning the stomach to pharynx. A pH electrode was placed $5 \mathrm{~cm}$ above the GOJ. Patients were studied at rest and during $15 \mathrm{~min}$ of standardised exercise on an exercise bike, before and after a meal (sausage or bacon with egg sandwich with $500 \mathrm{mls}$ of milkshake-736 calories). In addition subjects walked for $30 \mathrm{~min}$ in the post-prandial period.

Results 12 patients were male; median age 60 (range 35-76) years; six patients had LA A/B oesophagitis and 10 patients had LA C/D (5) or Barrett's oesophagus (5). Acid reflux episodes in patients with $\mathrm{HH}$ were due to tLOSR in $90 \%$, low LOS pressure in $6 \%$ and swallowing in $4 \%$, whereas in patients without $\mathrm{HH}$ they were due to tLOSR in $88 \%$, low LOS pressure in $4 \%$ and swallowing in $8 \%$. tLOSR appeared to be more frequent in patients with $\mathrm{HH}$ (13.5 (IOR 11.1-18.7) per hour vs 10 (IOR 7.6-15.6) per hour) but this difference fell short of statistical significance $(p=0.06)$. There was no difference in the proportion of TLOSR associated with acid reflux in patients with $(59 \%)$ and without $\mathrm{HH}(47 \%)$ but patients with $\mathrm{HH}$ were more likely to have impedance evidence of gas or liquid reflux during tLOSR than patients without $\mathrm{HH}(96 \%$ vs $83 \%$, p <0.001).

Conclusion Prolonged ambulant studies of the mechanisms associated with acid gastro-oesophageal reflux reveal that tLOSRs are the predominant mechanism associated with acid reflux in patients with oesophagitis or Barrett's oesophagus both with and without $\mathrm{HH}$. tLOSR appeared to be more common in patients with $\mathrm{HH}$ but this difference fell short of statistical significance. Patients with $\mathrm{HH}$ were more likely to have evidence of reflux during tLOSR.

Competing interests None declared.

\section{PWE-002 IBS IN NIGERIA; IS THERE A DECLINE IN PREVALENCE?}

doi:10.1136/gutjnl-2012-302514d.2

${ }^{1} \mathrm{C}$ A Onyekwere, ${ }^{*} \mathrm{~A}$ Asiyanbi, ${ }^{2} \mathrm{~J}$ Obi. ${ }^{1}$ Internal Medicine, Lagos state University college of medicine, Lagos, Nigeria; ${ }^{2}$ Internal Medicine, Lagos state University teaching hospital, Lagos, Nigeria

Introduction Background: IBS is a common functional gastrointestinal disorder that presents in both primary healthcare as well as gastroenterology clinic. Reports of prevalence of IBS vary depending on diagnostic criteria as well as geographical setting. Data from Nigeria reveal prevalence of between 26\% and 33\%. Aim: we set out to determine the prevalence of IBS in lagos population which is representative of the Nigeria society.
Methods Consecutive patients with recurrent abdominal pain who presented to the general outpatient unit of the three big referral hospitals in lagos between 2010 and 2011 were evaluated for the presence of IBs using the Rome 111 criteria.

Results 350 subjects were evaluated during the study period of which 65 (36 females) met the Rome 111 criteria giving a prevalence of $18.6 \%$. The IBS subtypes were IBS-C (33), IBS-D (18), and IBS-M (14). Occurrence of IBs was significantly associated with consumption of starchy food (rice, yam, potato, spaghetti, beans) and citrous foods. Majority of the IBs subjects (75\%) were positive for small intestinal bacterial overgrowth using the hydrogen breath test.

Conclusion This study has shown a lower prevalence of IBS (18.6\%) than the three previous reports from our setting $(26 \%, 30 \%, 33 \%)$.

Competing interests None declared.

\section{REFERENCES}

1. Olubuyide 10, Olawiyi F, Fasanmade AA. A study of irritable bowel syndrome diagnosed by Manning Criteria in an African population. Dig Dis Sci 1995;40:983-5

2. Ladep NG, Obindo TJ, Audu MD, et al. Depression in patients with irritable bowel syndrome in Jos, Nigeria. World Gastroenterol 2006;12:7844-7.

3. Okeke EN, Ladep NG, Adah S, et al. Prevalence of irritable bowel syndrome: a community survey in an African population. Ann Afr Med 2009;8:177-80.

\section{PWE-003 VASOPRESSIN CONTRACTS HUMAN ISOLATED STOMACH MUSCLE: POSSIBLE ROLE IN NAUSEA?}

doi:10.1136/gutjnl-2012-302514d.3

${ }^{1} \mathrm{~J}$ Broad, ${ }^{2} \mathrm{P} \mathrm{L}$ Andrews, ${ }^{1} \mathrm{G} \mathrm{J}$ Sanger. ${ }^{*}$ Neurogastroenterology Group, Blizard Institute, Barts \& The London SMD, OMUL, London, UK; ${ }^{2}$ Division of Biomedical Science, St George's University of London, London, UK

Introduction Circulating levels of vasopressin are raised in association with nausea in humans and in species with an emetic reflex, whereas in rats exposed to emetic stimuli, levels of oxytocin but not vasopressin are raised. ${ }^{1}$ One hypothesis is that vasopressin acts in the upper gut to help signal nausea, but in animals the concentrations which contract stomach muscle are usually higher than the concentrations measured in human plasma during nausea (around 10-200 pM). However, extreme species variations in gastric functions and genetics ${ }^{2}$ means that studies must now be conducted with human stomach.

Methods Human stomach was obtained at surgery following informed consent. After removing the mucosa, strips were cut parallel to the circular muscle and suspended between ring electrodes in tissue baths for isometric recording (Kreb's; $5 \% \mathrm{CO}_{2}$ in $\mathrm{O}_{2} ; 37^{\circ} \mathrm{C} ; 2 \mathrm{~g}$ tension). Electrical field stimulation (EFS) was applied at $5 \mathrm{~Hz}(0.5 \mathrm{~ms}$ pulse width, $50 \mathrm{~V}, 10 \mathrm{~s}$ ) every $1 \mathrm{~min}$, for sub-maximal responses. $\mathrm{N}=$ number of patients. All drugs were added non-cumulatively.

Results In the gastric antrum, EFS-evoked contractions were prevented by $1 \mu \mathrm{M}$ tetrodotoxin $(\mathrm{n}=3)$, attenuated by atropine $1 \mu \mathrm{M}(\mathrm{n}=3)$ and facilitated by the nitric oxide synthase inhibitor LNAME $0.3 \mathrm{mM}$ (by $11 \pm 7 \% \mathrm{n}=14)$. Vasopressin (100 pM-100 nM) caused a concentration-dependent increase in baseline muscle tension of $230 \pm 68 \mathrm{mg}, \mathrm{EC}_{50}=1.2 \mathrm{nM}$, corresponding to a contraction equivalent to $226 \pm 118 \%$ of the EFS-evoked contraction ( $n=1-4$ each concentration). However, there was no change in the magnitude of the contractions to EFS $(+14 \pm 12 \%$ change at $100 \mathrm{nM}$ ). Elevated muscle tension persisted for $>30 \mathrm{~min}$ in continued presence of the hormone $(100 \mathrm{nM}, \mathrm{n}=4)$. In preliminary experiments with gastric fundus, only $100 \mathrm{nM}$ vasopressin has been studied, being found to act similarly (an increase of 128 and $38 \mathrm{mg}$; $\mathrm{n}=2)$. Interestingly, oxytocin $(100 \mathrm{nM})$ also increased baseline muscle tension in the antrum (by 164 $\pm 64 \mathrm{mg}$, corresponding to an increase of $41 \pm 11 \%$ EFS; $n=3$ ), persisting for $>30$ min without affecting the magnitude of EFS evoked contractions ( $+13 \pm 4 \%$ change; $\mathrm{n}=3$ ). 